\title{
Research on the Management System of China's Lottery Industry
}

\author{
Yan Peng, Wei Song, Duanyang Ren \\ School of Public Affairs, University of Science and Technology of China, Hefei, China \\ Email: 435912695@qq.com
}

Received 7 December 2015; accepted 26 December 2015; published 29 December 2015

Copyright (C) 2015 by authors and Scientific Research Publishing Inc.

This work is licensed under the Creative Commons Attribution International License (CC BY).

http://creativecommons.org/licenses/by/4.0/

c) (i) Open Access

\begin{abstract}
With over 20 years of development, China's lottery industry has taken shape. But there are also some problems in the development, especially there are also some problems in the lottery management system. On the basis of analyzing the current situation of China's lottery industry, using the methods such as literature data, and comparative analysis, this paper discusses the direction and objectives of the China's lottery management system and reform, and puts forward suggestions to improve the lottery management system which provide guidance for the normative development of China's lottery industry.
\end{abstract}

\section{Keywords}

Lottery, Management System, Suggestions

\section{Introduction}

So far, the lottery has been widely recognized and accepted in most countries. Its main purpose is to raise the social idle funds and provide financial support for the government to carry out various undertakings; it can provide new employment opportunities and open up new labor services; it also can enrich people's cultural life and so on. The lottery industry is growing at an alarming rate which is known as "the sixth industry" in foreign countries. In our country, the purpose of the issuance of lottery is public welfare which is a non-profit behavior, and its main body is to guide everyone to do some contribution to the cause of public welfare. Because of its unique role in the economy, the lottery has been called the lottery economy [1]. With the rapid development of China's economy and the continuous improvement of the management level, the lottery industry will eventually become an important industry in China. The total sales of China's lottery were more than 309.3 billion yuan in 2014, an increase of $18.3 \%$ year on year. These funds can bring certain economic benefits and social benefits. Although China's lottery industry is developing rapidly, but because its operating time is short, there is still a 
big gap in the lottery management, publicity, marketing and innovation ability. The lottery industry in China is a new industry which is not mature, so there are still many drawbacks in the overall architecture which will has limitations to the economic and social. Therefore, this paper analyzes China's lottery management system, points out the necessity and importance of establishing and improving the current management system of China's lottery industry, and discusses the management system of the lottery industry which accords with the situation of China, in order to look for theoretical support and provide services for the development of lottery in China in the new period, so as to promote the sustainable and healthy development of China's lottery industry.

\section{Domestic and Foreign Research Situation}

Foreign research of lottery has been a long time. Most western countries have a clear legislative system and the issuance of norms. The current research focus is transferred to the operation mode, the innovation of the play, the psychology of the person who buys the lottery tickets, marketing strategy and economic factors, and so on. The management system of the lottery industry and the social benefits brought by lottery has become the focus of the scholars' research. For example, from the perspective of psychology, the study of Friedman and Savage considered that the desire, thoughts and emotions were the reasons for the people to "buy lottery" and "frequent purchase lottery" [2]. Becker further explained that the status had positive effect on the utility, and there were three reasons. First, if people had the same level of income, people at the high status would enable get what the people at low status could not get. Secondly, people at the high status would get obedience and respect from the people at low status which can make them obtain the psychological satisfaction. Thirdly, the wealth was considered as a signal, and usually people would also think that people at the high status have foresight, received a good education and have the knowledge to lead fashion [3]. Therefore, when the status was very important, people would spend a lot of time, energy and money to get a high status. About the social welfare brought by the lottery, Matheson \& Grote believed that the behavior people buys purchase lottery was rational. If the behavior was not rational, it could only be said that people often underestimate the value of the lottery so they buy less lottery, rather than buy more [4]. Oster believed that when the current jackpot amount was high, the amount people bet on the future installments was also increased [5]. It suggested that the lottery had certain addictive properties; it also could explained, if the award of the next phase or a few phase of the lottery was still no one in, more people would buy the lottery. And the transaction costs would be very low when people bet ahead of time, rather than the later bet.

The domestic researches of lottery system management are mainly concentrated in the regulation: It was pointed out in the study of Zhang Zhanbin that the regulation of lottery should focus on the following aspects: 1) the legislation specification; 2) the government regulation; 3) economic regulation and control; 4) audit regulatory. His study pointed out the direction of the research on the development of China's lottery and had strong pertinence [6]. There are many domestic scholars has made the analysis and research on China's lottery regulatory system during the last two years, such as Xu Lipan, Liu Wentao and so on. Through the deep analysis of the irrationality in theory and practice of China's lottery regulatory system, they put forward the direction of China's lottery regulatory reform and the principles we should follow on the basis of the world's major national lottery regulatory model [7]. At the same time, related lottery research institutions were set up in universities and research institutes. In July 2002, the first lottery specialized research institutes in our country was set up in Peking University-China's public welfare lottery institute. In October 2002, the Shanghai University of Sport and the Shanghai sports lottery management center signed an agreement and jointly established the Shanghai sports lottery center. In general, compared with the international economics, because the development time of China's lottery industry is short, and there is a considerable gap between the whole academic research level of the economy and the international level, so the research on lottery of China's economics is still in its infancy. As well, due to a variety of reasons, many important data are still shrouded in secrecy, and there also is certain discount in the accuracy of published data which virtually also brings great difficulties to the research of theory of lottery.

\section{Research Method}

\subsection{Literature Review}

We refer to the regulations, policies and other guidance documents of the State Council, Ministry of finance, Ministry of civil affairs and State Sports General Administration on the lottery, welfare lottery and sports lottery. We refer to the literature and books on the study of the gaming industry at home and abroad, and refer to author- 
itative newspapers about lottery in China. We also enter the world lottery association website and China lottery network to consult relevant information.

\subsection{Survey Analysis}

We use the methods of visiting, discussion and questionnaire investigation, respectively communicate with the lottery management, practitioners of lottery betting station, lottery buyer, economic scholars and the general public, and listen to their opinion of the problems current in the lottery industry developing and the suggestions to solve the problem.

\subsection{Comparative Analysis}

We make the comprehensive analysis of the literature about the lottery management system both at home and abroad, learn from the advanced management experience at broad and put forward the model of management system which is suitable to China's lottery, in order to provide the theoretical reference for relevant departments in China.

\section{The Situation of the Management System of China's Lottery Industry}

\subsection{The Regulatory System of China's Lottery Industry}

The regulatory system of China's lottery industry is made up of the State Council, Ministry of finance, Ministry of civil affairs and State Sports General Administration. They are responsible for overseeing lottery responsibilities to ensure the healthy operation of lottery in China.

\subsubsection{State Council}

The State Council is the highest lottery management department in China. The article 1 of "The State Council on further regulating the lottery management" states: "The approval rights of lottery issuance are concentrated on the State Council, all localities and departments have no right to approve lotteries.” The examination and approval includes: the examination and approval for the kinds of lottery tickets, and there are welfare lottery tickets, sports lottery tickets and soccer lottery approved by the state to issue at present; the examination and approval for subject of lottery issuance. The article 4 states: "Without the approval of the State Council, any place, departments, organizations and individuals are not allowed to issue or issued in a disguised form in the People's Republic of China.”

\subsubsection{Ministry of Finance}

The Ministry of finance is the competent authorities of lottery authorized by the state council. It is mainly responsible for drafting the regulations and policies of the national lottery management and doing the regulatory and management of the lottery market, as well as the issuance and sales activities. It also studies and formulates the policies for use of lottery funds together with the Ministry of Civil Affairs and the State Sports General Administration, and supervises the remit, distribution and use of lottery funds. Local financial departments at all levels are the administrative department of lottery market in this region which are responsible for the regulation of the lottery market in accordance with the law. Their responsibilities mainly include two categories: One is to maintain the normal order of the lottery market; two is to manage the lottery funds [8]. It is stated in "Ministry of Finance on Strengthening and Improving the lottery finance and lottery funds management," that, the finance department is responsible for the financial management of the lottery agency in internal financial sector. The financial revenue and expenditure budget and final accounts of lottery agency is not included in the budget of the administrative department, and it is separately reported to the financial departments at the same level for approval.

\subsubsection{Ministry of Civil Affairs and State Sports General Administration}

The Ministry of civil affairs and State Sports General Administration respectively is the administrative department in charge of the issuance of welfare lottery and sports lottery. According to the laws, regulations and the relevant provisions of the State Council and Ministry of finance, they are responsible for the unity management of the lottery issuance and sales. In 2001, the State Council issued the "Notice on further standardize the lottery management”: according to the relevant state laws, policies and regulations, the Ministry of civil affairs and 
State Sports General Administration study and formulate the specific measures of the issuance, sales and funds management of the welfare lottery and sports lottery, and organize the implementation; they are responsible for the study and formulation the development plans of lottery in their system; they ensure remit the full lottery funds to the financial special account timely; they strengthen the management of lottery issuance and sales organizations, make efforts to reduce costs and expand the scale of the issuance. Civil affairs department and sports department at all levels are the administrative department of welfare lottery and sports lottery in this region which are responsible for the issuance and sales of the lottery in this region [9]. In short, "The State Council has the approval authority of issuance, the Ministry of finance mainly grasp the lottery issuance policies under the authorization of the State Council, and the Ministry of civil affairs and the State Sports General Administration mainly are responsible for the developing and implementation the rules of the lottery." The current framework of the lottery management system is shown in Figure 1.

\subsection{The Issuance System of China's Lottery}

The issuance of lottery sales in China is implemented by the lottery issuance and sales organizations and lottery retailer. The lottery issuance and sales organization refers to specialized organizations which national franchise to responsible for the lottery issuance and sales, including China Welfare Lottery Management Center, China sports lottery management center and the provincial and municipal center. Let's look a bit more closely and use the distribution system of the welfare lottery as an example:

China welfare lottery management center is the directly affiliated undertaking institutions under the Ministry of civil affairs which is the unique issuer of national welfare lottery. Authorized by the Ministry of Civil Affairs, it is responsible for the issuance and sales operations of the national welfare lottery. It does the business leadership and comprehensive monitoring of all the welfare lottery organizations and organizes the implementation according to the provincial administrative areas. It is responsible for the specific works such as the unified issuance, unified printing, making technical regulations and the system management, etc. Provincial Welfare Lottery Center is the secondary unit of welfare lottery issuance which is under the leadership of the local civil affairs department, as well as it accepts the business leadership and regulatory and inspection of the China Welfare Lottery Management Center. Authorized by the China Welfare Lottery Management Center, it specializes in lottery sales activities in the provincial administrative areas. The prefectural-level, municipal welfare lottery sales organizations are grassroots marketing units which is under the leadership of the local civil affairs department, as well as it accepts the business leadership and regulatory and inspection of the China Welfare Lottery Management Center, and their work mainly is to sale the lottery directly. At present, China Welfare Lottery sales system has 32 sales organizations, 320 prefecture-level sales organization, more than 100,000 sales outlets and more than 300,000 employees in every province, autonomous region, provincial-level municipality and city specifically designated in the state plan, and it has established a huge sales network. After more than 20 years of

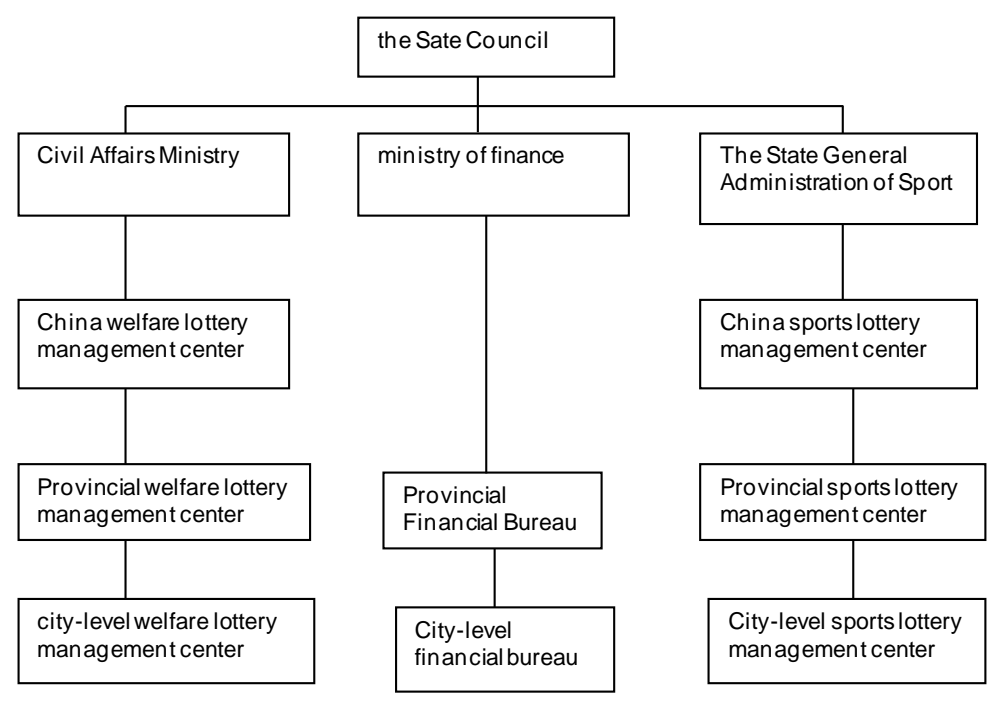

Figure 1. The framework of the lottery management system. 
the lottery sales practice, it has formed a relatively complete system of issuance and sales: The issuance and sales system of welfare lottery issuance considers the "Helping the old, Helping the Disabled, saving the orphan, assisting the poor and relieving the people in stricken areas" as the aim, and it is based on the uniform distribution. It also considers the three level management and network marketing as the main body, and is supported by the technological systems. It effectively ensures the longitudinal management and lateral contact of the issuance and sale of welfare lottery and plays an important role for promoting the development of lottery market.

\subsection{The Distribution System of Funds}

The distribution of the lottery income is divided into two levels: the first one is the primary distribution, namely the distribution of lottery sales income. The situation of the current lottery sales income is: the proportion of the funds which is returned to the winner is not less than $50 \%$, the proportion of public welfare fund is no less than $30 \%$, the proportion of operating costs is not more than $15 \%$. The other one is redistribution, and it mainly aims at the segmentation and use of the lottery public welfare fund. The distribution proportion and patterns of the public welfare fund of China's current lottery has witnessed great changes. It changes the situation that the public welfare funds was simply distributed and used among civil affairs and sports department at all levels in the past time, and begins to gradually form the situation and mechanisms that Nation, civil affairs and sports department share with the public welfare funds [10]. China's current public welfare fund use the pattern of financial management, and its basic key points include:

1) Public welfare fund is used to the relevant social public welfare undertakings determined by the state, and it shall not be used to balance the budget; $20 \%$ personal income tax will be imposed to the person whose single prize money is more than 10,000 yuan, and the tax will be included into the general budget allocations of local government.

2) The distribution policy of public welfare funds of lottery has been adjusted. First, The public welfare funds is distributed by $50 \%$ between the central government and local governments; secondly, the public welfare funds of lottery concentrated by the central government is distributed by $60 \%, 30 \%, 5 \%$ and $5 \%$ to the social security funds, special public welfare funds, Ministry of Civil Affairs and the General Administration of Sport. Thirdly, the public welfare funds of lottery concentrated by the local government are checked by the welfare lottery and sports lottery separately. The use of the funds adhere to the aim of the lottery issuance, and the distribution principles are studied and determined by the Ministry of finance, Ministry of civil affairs and State Sports General Administration together.

3) In accordance with the principle of "Separating revenue and expense", the income of lottery issuance is carried out special account management. The public welfare funds of lottery and the distribution costs must be included in the financial accounts, and the costs must comply with the financial management system of the lottery issuance and sales organization and management system of public welfare funds of lottery. The national audit institutions should strengthen the audit of the lottery issuance and the raising, distribution and use of the public welfare funds of lottery, and publish the audit results to the public.

\section{The Problems Existed in the Management System of China's Lottery Industry}

\subsection{The Legal Construction Related to Lottery Lags behind Seriously}

The legislation of lottery industry in most countries around the world is before the issuance of lottery, but the legislation of lottery industry is after the issuance in China. Having been issued since 1987 in China, there is not a law or regulation which can be unified management of the national lottery market. The current legal document with most legally binding is the administrative regulations issued by the State Council, but the legal documents which play the main role is set by the Ministry of Finance and Ministry of Civil Affairs and other relevant departments. This management mode which only relies on the document and provisions of the government departments can't meet the demands of reality. Lotteries have gambling nature. While the existing provisions of our criminal law prohibit all forms of gambling, but there is no corresponding legal norms which permit the lottery issuance and regulate the operation of lottery. The current regulations are biased towards the principle and we can't find the details of the penalty which make only some of its provisions useless. They are not very clear regulations on the specific problems such as the lottery issuance, the distribution and use of funds, the opening of financial management and information disclosure, the winning rules, personnel qualification requirements and so on. Because the legal system related to the lottery is severely lagged, the judicial organs and lottery man- 
agement departments can’t identify the nature of all kinds of misconduct appearing in the process of the lottery issuance, and they are difficult to carry out effective punishment.

\subsection{The Regulatory System of Lottery Is Not Well: The Dislocations of Inner Regulatory System and the Absence of External Regulatory}

The current management system of lottery and the regulatory pattern, in essence is a kind of ternary regulatory. Namely, The State Council has the regulatory power of the approval of lottery subject, the type and amount of lottery issuance, but with the rapid development of lottery industry, the approval of amount of lottery issuance has been basically cancel; The Ministry of finance is only "responsible for drafting, formulating the regulations and policies of the national lottery management and doing the regulatory and management of the lottery market, and it also supervises the lottery issuance and sales activities. It also studies and formulates the policies for use of lottery funds together with the Ministry of Civil Affairs and the State Sports General Administration, and supervises the remit, distribution and use of lottery funds."; The Ministry of civil affairs "study and formulate the specific measures of the issuance, sales and funds management of the welfare lottery and sports lottery, and organize the implementation according to the laws, regulations and the relevant provisions of our country; they ensure remit the full lottery funds to the financial special account timely, strengthen the management of lottery issuance and sales organizations, and make efforts to reduce costs and expand the scale of the issuance" [11]. In the actual operation, the State Council has the very strong rigidity on the approval of the lottery subject and types. Because once the two problems are determined, there is not much change on them. In addition to declaring the monopoly of the State on the lottery operators, the regulatory of these two problems lacks the realistic significance. The Ministry of Finance which has a regulatory authority on the surface also faces many problems which make its regulatory powerless. The main problems include: 1) According to the present administrative management system, the national ministries are equal with others. The departments at all levels only accept the leadership of its higher authorities, and they do not accept the management of other departments. Under China's current administrative system and legal environment, the effect of the lottery market mode is very limited, and the mode is "administrative departments supervise administrative departments". 2) Regulatory powers also lack the necessary mechanism of protection. The lottery office of the comprehensive department is responsible for the lottery regulation of Ministry of Finance. But the level of this office is low, and the personnel are less. The provincial and municipal financial departments lack of the specialized organization and personnel configuration which further restricts the regulatory functions of the lottery. Therefore, rather than the Ministry of Finance is in the exercise of regulatory functions, the civil administration and sports departments are in the implementation of self-regulation. 3) There are many problems about the regulatory of the civil administration and sports departments. In the case of welfare lottery, from the relationship between the Ministry of Civil Affairs and the China welfare lottery management center, the China welfare lottery management center is a public institution organization affiliated to the Ministry of Civil Affairs, and their relationship is that of leading and being led. Thus, that the civil affairs departments supervise their subordinates organizations is internal self-supervision. Because of the interests of the departments, one can imagine the effect of supervision.

While the inner regulatory system is malposed, the external regulatory of China's lottery industry is serious absent. As a result, the phenomenon of violate the law and discipline are continuously increasing in the process of the lottery issuance, sales and the use of public welfare funds This phenomenon causes the bad social influence, and even to the extent that the government credibility which is considered as the soul of lottery issuance is shaken, so we should pay great attention to it. 1) The specific situation of the raise, distribution and use of China's lottery funds is difficult to obtain. The existing lottery regulations and internal documents are not clear enough for the several specific questions such as the lottery issuance, the distribution and use of funds, the opening of financial management and information disclosure, the winning rule, qualification requirements of working people, which cuts off the possibility and operability of the external regulatory to a certain extent and makes the external regulatory become a mere formality. 2) A variety of media is restricted by a lot in the report in terms of lottery-related content and can not effectively play their supervisory functions.

\subsection{In the Issuance and Sales System of Lottery, the Functions of the Government Fail to Be Separated from Those of Enterprises}

China's issuance and sales system of lottery established by the current legislative framework is called "duopoly direct competition mode" by the critics. The direct result of concentrating the operation right of lottery market 
into the two governments is administrative power "absolute monarch". The administrative behavior and market behavior are seamless. In the market, the "consumers" and "operator" is asymmetric in these aspects such as legal status, the participation of rules and information acquisition. Because of the lack of an independent third party arbiter in the market, the disputes happened in the market can't be settled institutionalized. Even more serious is that the "functions of the government fail to be separated from those of enterprises." Severely restricted the establishment and improving of the market rules which has become the handicap of the lawmaking of lottery. The reason is very simple. If the market operators themselves are the dominant force of the establishment of the market rules, how can we expect it to do against humanity? Secondly, the "functions of the government fail to be separated from those of enterprises" lead directly to the high costs of issuance. The lottery funds are divided into three sections. According to the current legislative framework, 50\% of the funds are used for the return award, 35\% of the funds are used for public welfare funds and 15\% are used for the cost of issuance. The return award and public welfare funds are regulated by some documents issued by the State Council, People's Bank of China and the Ministry of Finance. But the cost of issuance basically regulated by the documents issued by both the civil affairs department and sports department. A group of worrying data is that, in the countries which the lottery management system is relatively perfect such as Britain and America, the cost of issuance account for 5\% to $10 \%$ of sales. But in China, the cost of issuance accounted for $20 \%$ in 2002, and it was adjusted to $25 \%$. From 2000 to 2004, the cost of issuance of the two lottery institutions were 3.62 billion yuan, 5.777 billion yuan, 5.785 billion yuan, 6.021 billion yuan and 5.71 billion yuan, and it basically remained at around 6 billion yuan in recent years. On the one hand, such a huge cost of issuance is used circuitously in the company which is directly invested by the lottery institutions. they not only are used for personal rewards, and even used for purchase of property and rental. Eventually they are transformed into the sector interests of equitable distribution of benefits in system. On the other hand, after the lottery institutions at all levels established according to the administrative class cut down the cost of issuance time and time again, the grassroots lottery institutions are faced with the dilemma that the cost of issuance is insufficient and they are unwilling to bear the risk of lottery sales is at a loss. In order to shift risk, the lottery underwriting and lottery resellers which are illegal are often found in the news. Because of the gray of underwriter and the regulatory gap, some malignant lottery fraud caused a heavy blow to the development of lottery.

\subsection{The Problems of the Distribution and Use of Lottery Public Welfare Funds}

China's current lottery public welfare funds management mode is gradually formed in the special historical environment, to a certain extent, it embodies the essential requirement of the public welfare funds. However, compared with the requirement of market economy system, there are many problems. 1) The use of public welfare funds. At present, the civil administration departments and sports departments are responsible for distribution and use of the public welfare funds. Especially the usable range of the part funds remaining for the use of the local departments is relatively narrow, showing the characteristics of departmentalization. This narrow range of use and the funds distribution system which give priority to "rules" limit the use of the public welfare funds [12]. On the other hand, it reflects that the funds distribution between sectors is unreasonable because of the "monopoly of department" of the lottery public welfare funds, and this irrationality leads to inefficient use of lottery and disguised waste. It was pointed in the Audit Announcement No. 5, 2006 issued by the National Audit Office: in the budget of the use of sports lottery public welfare fund in 2005, the State Sports General Administration arranged 22.5 billion yuan used for the national fitness program”. By the end of 2005, the State Sports General Administration actually distributed 197 million yuan, and there are still 28.14 million yuan is not approved to distribute. 2) The current distribution system of lottery public welfare funds is not conducive to fully mobilize the enthusiasm of the local. According to the current distribution system of lottery public welfare funds, in the premise of the public welfare funds cardinality remains unchanged, the proportion of the public welfare funds concentrated by the central departments will continue to increase with the growth of the national lottery issuance. However, in the case of the growth of lottery issuance around is not balanced, the provinces which the issuance is smaller or even negative growth are forced to bear the proportion which doesn't fit with the situation of themselves, because of “a rising tide lifts all boats” effect [13]. It is not conducive to fully mobilize the enthusiasm of the local departments to development the lottery industry. 3) The process of the raising, distribution and use of public welfare funds and the social supervision is not standardized and transparent enough. The supervision and restraint on the public welfare funds is not in place, the financial system is not standardized, and there are illegal use and misappropriation of funds. The current lottery management system proposes that the 
management of public welfare funds should announce to the public, but there is no specific operating system. One of the most fundamental reasons is that the public welfare funds are included into the budget management of relevant department which make the announcement is difficult to operate. The public welfare funds which are included into the department budget management need to obey the general budget management system, and it is often difficult to distinguish the concrete use of the general budget funds and the public welfare funds. The public welfare funds are dispersed in different departments, so the financial sector can not do the unified management and supervision on their use, and the relevant information is not centralized. Therefore, the governments only announce the raising and primary distribution of the public welfare funds, and the specific use and supervision is hard to announce.

\section{The Measures of Improving Our China's Lottery Management System}

1) We should improve the system construction. System is the premise for all works to carry out. If we want to make each work be carried out to a unified goal in a given track, it is necessary to establish an institutional guarantee. After the content of improving the management system is established, the system needs to keep up the revision and improvement. Only the system is improved, we can ensure the realization of the goal to adjust the management system.

2) We should speed up the legal system construction. The legal system is the foundation and guarantee of each work. In the process of improving the lottery management system, we will inevitably encounter some problems which the existing policies and regulations can not explain and determine. If these problems are not resolved, it will restrict the processes and speed of improving the management system and become a stumbling block. Therefore, we should speed up the pace of the legal construction of lottery industry to solve the worries behind of the development of lottery management system.

3) We should clear the government responsibilities. It should be said that the problems of lottery management belong to the big subject of the government institutional reform. In recent years, the government has been committed to changing functions and institutional reform, and they are in the process of exploration, demonstration, test and development. On the issue of lottery, the government functions not only need to be changed, but also to be made clear through a certain form. So that government transformation should be prompted by improving the lottery management system.

\section{References}

[1] Wang, Y.M. (2005) The Comparative Analysis of Lottery Operation and Management System. Financial, 4, 79-80.

[2] Friedman, M. and Savage, L.J. (1948) The Utility Analysis of Choices Involving Risk. Journal of Political Economy, 56, 279-304. http://dx.doi.org/10.1086/256692

[3] Becker (2000) Status Lotteries and Inequality. Free Press, New York.

[4] Matheson, V.A. and Grote, K.R. (2005) Examining the Halo Effect in Lotto Games. Financial Analysis Journal, 58, 14-21.

[5] Oster, E. (2002) Why Do People Play the Powerball? Harvard University. Senior Honors Thesis.

[6] Zhang, Z.B. (2006) Research on China's Lottery Industry Government Regulation. Tianjin Institute of Physical Education, 21, 33-37.

[7] Xu, L.P. (2004) Study Lottery Regulatory Mechanisms. Chinese Administration, 12, 56-59.

[8] Zhu, T. (2005) The Problems, Causes and Countermeasures of Lottery Market in Our Country. China Economic \& Trade Herald, 16, 48-49.

[9] Liu, Y.T. (2001) The Discussion of the Probability of Lottery. Mathematics Bulletin, 7, 23-24.

[10] Liu, Z.D. and Li, Z.F. (2006) The Development of Foreign Lottery and the Reform of China's Lottery Ticket Management System. Journal of Sports Adult Education, 3, 45-47.

[11] Zhu, X. and Wang, G.H. (2005) The Problems and Countermeasures Analysis in the Development of China's Lottery. Journal of PublicEconomics, 4, 202-213.

[12] Garrett, Thomas (2001) An International Comparison and Analysis of Lotteries and the Distribution of Lottery Expenditures. International Review of Applied Economics, 15, 213-227. http://dx.doi.org/10.1080/02692170151137096

[13] Cook, P.J. and Clotfelter, C.T. (1993) The Peculiar Scale Economies of Lotto. The American Economics Review, 5, 64-70. 